\title{
Editorial:
}

\section{Narrativas contemporâneas e desafiadoras construções do}

\author{
futuro
}

\section{Editorial:}

\section{Contemporary narratives and challenging future constructions}

\begin{abstract}
Alexandre Carauta
Doutor em Comunicação pela PUC-Rio e Editor da Revista ALCEU. Pontifícia Universidade Católica do Rio de Janeiro, Departamento de Comunicação, Rio de Janeiro (RJ), Brasil.

Vera Follain de Figueiredo

Doutora em Letras pela PUC-Rio e Editora da Revista ALCEU.
\end{abstract} Pontifícia Universidade Católica do Rio de Janeiro, Departamento de Comunicação, Rio de Janeiro (RJ), Brasil.

A Alceu 43 conjuga reflexões em torno de um assunto recorrente nas narrativas cinematográficas e literárias, e nos debates acadêmicos: distopia. Intensificado nos tempos convulsos da pandemia, o tema desdobra-se em múltiplas incursões teóricas, decorrentes de constantes indagações, inquietações. Se toda utopia nasce da busca imaginária de alternativas à ordem vigente e, portanto, se caracteriza mais pela negatividade do que pela afirmação de uma sociedade perfeita, utopia e distopia seriam duas faces da mesma moeda? A distopia configura-se como uma utopia pelo avesso? Constitui um gênero narrativo? Como se constrói a relação entre distopia e presentismo no universo ficcional?

Ao encontro dessas e outras questões afins, confluem os oito artigos do dossiê Distopia e narrativas contemporâneas: a difícil arte de imaginar o futuro. A coletânea contempla diversas perspectivas 


\section{ALCEU}

ISSN: $2175-7402$

associadas às implicações estéticas, éticas e políticas da representação apocalíptica do futuro na produção cultural das duas últimas décadas.

Dialogam com esse eixo temático os demais quatro artigos da edição. Reforçam o estímulo da revista ao pluralismo e à densidade científica, compromisso renovado ao longo das duas décadas da publicação.

Utopia, distopia... Pandemia! Os sonhos de futuro e a temporalização das imaginações do porvir abre o dossiê. Cristina Teixeira e Mirella Pessoa partem de sonhos do futuro, no mundo contemporâneo, para mapear a fragilização do pensamento utópico e o avanço da imaginação distópica. Mais do que contrapontos, observam as autoras, utopia e distopia representam formas de imaginar o futuro relacionadas com dinâmicas de poder e experiências temporais. "O presentismo nos coloca isolados - física e politicamente - em um presente sufocado por previsões de futuro que se expandem num agora que parece se repetir", apontam Cristina e Mirella.

Na sequência, llana Feldman navega por proposições da historiadora Annette Wieviorka, do filósofo e historiador Georges Didi-Huberman e da escritora Svetlana Aleksiévitch, entre outras referências, para entrelaçar narrativas audiovisuais, políticas da memória, pedagogia e imaginação, num contexto de catástrofes ambientais e pandemias globais. "Holocausto" (1978) a "Chernobyl" (2019): O que pode o audiovisual face a um passado traumático e a um futuro ameaçado? discute as possibilidades do audiovisual face a formas de violência de Estado.

A narrativa audiovisual instiga também o percurso reflexivo de Breno da Silva Carvalho e Raquel Assunção Oliveira em Inventividade e desvio na série Ad Vitam: As vicissitudes humanas em contexto distópico. Carvalho e Oliveira navegam no universo da referida série, criada por Sébastien Mounier, para debater a perpetuidade da vida e as motivações subjetivas individuais à luz de referenciais socioantropológicos e comunicacionais contemporâneos. Ao considerar a vivência em ambiente distópico, o artigo analisa questões acerca dos efeitos da saúde, do tempo e da construção de projetos de vida a partir do enredamento narrativo da série.

O audiovisual é igualmente o pano de fundo para David Castro Netto e Roger Domenech Colacios discutirem visões distópicas do futuro alusivas ao meio ambiente. Em Uma terra somente: distopia ambiental no cinema hollywoodiano (séc. XXI), os autores constroem suas apreciações a partir de três filmes: 2012 (2009), Elysium (2013) e Interestelar (2014), obras de ficção científica nas quais habita um fim do mundo esboçado pela crise ambiental. 
A relação entre cinema, ficção e um futuro ameaçado pelo colapso ambiental permeia também o artigo de Antonio Hélio Junqueira Cli-Fi e narrativas distópicas do futuro: O espaço da ironia em Downsizing. O texto explora os conceitos bakhtinianos da linguagem do riso na conformação dos sentidos sociais para discutir, a partir da crítica ao filme referenciado no título, as dimensões discursivas da ironia na narrativa distópica de um futuro que se confronta com os impactos capitalistas sobre o clima global. Junqueira identifica uma eficácia discursiva da ironia para "abordar o comportamento humano irremovível frente às promessas dos prazeres inesgotáveis do lazer permanente e do consumismo". Ele ainda detecta um "fracasso da máquina autopoiética guattariana na produção de novas subjetividades e do agenciamento coletivo para a produção de novas realidades".

Já Rafael Pinto Ferreira de Queiroz analisa o clipe musical Nave (2019), da cantora Xênia França, sob a perspectiva do afrofuturismo como instrumento crítico ao racismo. Com base em referências como Dery e Tate, Corbett, Eshun e Womack, Queiroz desvela sentidos que emergem do movimento político-estético negro e transnacional. Cruzando a órbita prum novo mar: Xênia França e o afrofuturismo no videoclipe de Nave aporta na sugestão de que a artista cultiva "uma ligação espaço-temporal tecida pelas encruzilhadas do Atlântico negro, especialmente na música afrodiaspórica".

O cinema distópico brasileiro dos últimos anos é o fio condutor do sétimo artigo do dossiê, Distopia, Utopia, Catarse: o cinema sintomático de Kleber Mendonça Filho. Baseadas em trabalhos referentes às chamadas teorias de cineastas, e em estudos de Alexandre Astruc, Frantz Fannon e Ismail Xavier, Sandra Fischer e Aline Vaz centram o enfoque no filme Bacurau (2019), de Kleber Mendonça Filho e Juliano Dornelles. Um longa “cujo universo fictício sintomaticamente distópico estimula no espectador, potencialmente, uma vivência catártica capaz de levantar reflexões acerca da experiência estética como uma experiência política e de resistência".

Outra vertente da produção cinematográfica brasileira irriga os territórios analíticos de Cezar Migliorin e Felippe Schultz Mussel no oitavo e último artigo do dossiê, O cinema de guerra da Ceilândia: As máquinas de Adirley Queirós contra a utopia de Brasília. Fundamentados no pensamento de Deleuze e Guattari, os autores mergulham nas tramas de insurreição da periferia contra a capital delineadas por Queirós - sobretudo "na fricção entre os corpos dos personagens, as arquiteturas urbanas e diferentes tipos de máquinas". Eles investigam como esse cinema de guerra "forja seus ataques àquele projeto utópico de cidade". 
Não menos complexa se mostra a temática política do conjunto de reportagens "Um mundo de muros", publicado em 2017 pela Folha de S. Paulo. Para Wagner Souza e Silva, as imagens dessa série ilustram a imersão multimídia do fotojornalismo e situam-se no aporte estético utilizado pelo repórterfotográfico Gustavo Pellizzon no trabalho experimental "Fotografias que respiram". Constituem, portanto, "uma sensível estratégia para abordar a complexidade política do tema da série". Tal olhar é esmiuçado em Imagens que respiram: O fotojornalismo multimidiático na série "Um mundo de muros".

Reflexões sobre registros imagéticos no contemporâneo acompanham o texto seguinte, Paroxismo das câmeras cotidianas: desafios narrativos. Angela Maria Meili discute como o regime paroxístico das câmeras cotidianas influencia a produção do conhecimento histórico, reconhecendo os limites de representação da narrativa linear. Ao refletir sobre a narratividade, o ensaio considera a "dimensão do arranjo material dos objetos técnicos e a profusão de registro que reconfiguram a memória e a experiência com a temporalidade e levam à necessidade de reelaboração das ferramentas interpretativas".

Debruçada também sobre a construção de representações e significados no contemporâneo, Carla Baiense indica como narrativas estudantis tensionam os limites da participação juvenil na esfera pública e imprimem novos sentidos à vida escolar. Em Narrativas juvenis e socialização reflexiva: Do que falam os jovens quando falam de mídia?, a autora apresenta os resultados preliminares da pesquisa "Visões da juventude: midiatização, letramento e produção de sentidos", realizada numa escola pública de Niterói, região metropolitana do Rio.

Não menos articulado à hipermidiatização contemporânea é o 120 artigo da Alceu 43, Abordagens Teóricas para Estudo da Teatralidade em Performances Midiáticas: Dramas, roteiros, ações. Com base na premissa de que encenações em redes sociais digitais despertam pontos de vista conflitantes sobre indivíduos, Thiago Soares analisa como as controvérsias nesses ambientes autorreferenciais de alta visibilidade modulam teatralizações de conflitos. Tais mecanismos acionam "uma pragmática da ação em rede" em diferentes estratos performáticos.

Os textos compilados nesta edição compõem, assim, um painel com o qual acreditamos enriquecer o debate sobre os caminhos contemporâneos, seus dilemas e ambiguidades, suas narrativas e temporalidades. Um debate em que se revigora a ponte entre comunicação, política e cultura.

Boa leitura! 
Alexandre Carauta

ORCID: https://orcid.org/0000-0002-3607-8710

Pontifícia Universidade Católica do Rio de Janeiro, Departamento de Comunicação, Rio de Janeiro (RJ), Brasil

Doutor em Comunicação pela PUC-Rio

Vera Follain de Figueiredo

ORCID: https://orcid.org/0000-0003-0142-6938

Pontifícia Universidade Católica do Rio de Janeiro, Departamento de Comunicação, Rio de Janeiro (RJ), Brasil

Doutora em Letras pela PUC-Rio

Este artigo é publicado em acesso aberto (Open Access) sob a licença Creative Commons Attribution Non-Commercial (CC-BY-NC 4.0), que permite que outros remixem, adaptem e criem a partir do seu trabalho para fins não comerciais, e embora os novos trabalhos tenham de lhe atribuir o devido crédito e não possam ser usados para fins comerciais, os usuários não têm de licenciar esses trabalhos derivados sob os mesmos termos. 